\title{
A Model of Mindful Parenting: Implications for Parent-Child Relationships and Prevention Research
}

\author{
Larissa G. Duncan · J. Douglas Coatsworth • \\ Mark T. Greenberg
}

Published online: 2 May 2009

(C) The Author(s) 2009. This article is published with open access at Springerlink.com

\begin{abstract}
This paper introduces a model of "mindful parenting" as a framework whereby parents intentionally bring moment-to-moment awareness to the parent-child relationship. This is done by developing the qualities of listening with full attention when interacting with their children, cultivating emotional awareness and self-regulation in parenting, and bringing compassion and nonjudgmental acceptance to their parenting interactions. First, we briefly outline the theoretical and empirical literature on mindfulness and mindfulness-based interventions. Next, we present an operational definition of mindful parenting as an extension of mindfulness to the social context of parent-child relationships. We discuss the implications of mindful parenting for the quality of parent-child relationships, particularly across the transition to adolescence, and we review the literature on the application of mindfulness in parenting interventions. We close with a synopsis of our own efforts to integrate mindfulness-based intervention techniques and mindful parenting into a well-established, evidence-based family prevention program and our recommendations for future research on mindful parenting interventions.
\end{abstract}

Keywords Parenting $\cdot$ Mindfulness $\cdot$ Family $\cdot$ Prevention

L. G. Duncan $(\bowtie)$

Osher Center for Integrative Medicine, School of Medicine, University of California, San Francisco, UCSF Box 1726,

San Francisco, CA 94143-1726, USA

e-mail: duncanLa@ocim.ucsf.edu

J. D. Coatsworth - M. T. Greenberg

Prevention Research Center and Department of Human

Development and Family Studies, Pennsylvania State

University, University Park, PA, USA

\section{Introduction}

Mindful parenting has been described as a fundamental parenting skill or practice (Steinberg 2004; Kabat-Zinn and Kabat-Zinn 1997), and it has been proposed that fostering everyday mindfulness in the context of parenting and parent training is one avenue for improving the effectiveness of parenting interventions (Dumas 2005). However, empirical evidence on the role of mindfulness in parenting is sparse and a comprehensive model of mindful parenting has not yet been developed. The model of mindful parenting we offer extends the concepts and practices of mindfulness, defined here as "the awareness that emerges through paying attention, on purpose, in the present moment, and nonjudgmentally to the unfolding of experience moment by moment" (Kabat-Zinn 2003, p. 145), to the social context of parent-child relationships. We draw from the theoretical and empirical literature on mindfulness and mindfulness-based interventions to propose a model of mindful parenting that has novel implications for understanding healthy parent-child relationships and for improving family-focused preventive interventions. We illustrate our model with examples of how mindful parenting and mindful parenting interventions may be beneficial for parent-child relationships during the child's transition to adolescence.

\section{Theoretical Foundations of Mindfulness Applied to Parenting}

Mindfulness meditation, the disciplined practice of bringing mindful awareness to moment-to-moment experience, has been at the core of all of the major streams of Buddhist practice and scholarship for centuries (Goldstein 2002). 
However, mindfulness is also considered to be a capacity inherent to humans independent of any affiliation with Buddhism (Kabat-Zinn 2003) and has recently been the focus of psychological practice, theoretical discourse, and research in Western psychology. According to longstanding Buddhist teachings, mindfulness has the potential to provide freedom from the egoistic, hedonic treadmill of continually avoiding discomfort and seeking pleasure from outside sources that are ultimately unsatisfying and shortlived (Kornfield 1977; Rahula 1959). The cultivation of mindfulness is thought to provide an antidote to states of being unaware (e.g., not noticing or not paying attention to thoughts, feelings, and sensations) and aversive (e.g., avoiding the experience of what is happening in the present moment) (Goldstein 2002). From this perspective, mindfulness can promote a deeper and more enduring sense of well-being found through simply being with whatever is happening in the present moment, with a recognition that it will pass and be replaced by a new experience in the next moment (Kabat-Zinn 2003; Wallace and Shapiro 2006). Mindfulness thus allows for greater flexibility and an accuracy in perception of what is happening in the moment (found through no longer being unaware), as well as greater acceptance and less reactivity to whatever is taking place on a somatic, cognitive, affective, or behavioral level (and therefore no longer avoidant).

According to recent Western psychological theory, mindfulness is "a receptive attention to and awareness of present events and experience" that allows for full awareness of what is happening in the moment (Brown and Ryan 2003). In this view, compatible with Eastern tradition, mindfulness is a quality of consciousness posited to encompass both a clarity of awareness and the ability to flexibly shift between broad awareness and focused attention during moment by moment experience (Brown et al. 2007a). While states of mindfulness of attention and awareness may appear easy to attain for brief periods of time, it is often quite challenging to develop a sustained practice of continually reorienting one's mind to being in the present moment and being open to experience (a more dispositional tendency toward mindfulness). Our natural attention processes typically hold an object or experience in focused attention only for a short period before other affective and cognitive processes "respond" to it. Moreover, our history of life experiences frequently condition these responses such that we automatically appraise and judge almost everything we encounter with little or no conscious awareness (Bargh and Chartrand 1999). Usually these primary appraisals are basic judgments of an object or experience as "good" or "bad" and these automatic judgments, along with cognitive biases created by our beliefs, opinions, and expectations, may lead us to distort the reality of what is currently taking place. Mindful attention and awareness are intended to overcome these distortions and provide a clearer awareness of one's immediate experience. From this perspective, maintaining a mindful awareness allows for exercising choice in responding to experience and provides an alternative to engaging in habitual, or "automatic," cognitive and behavioral reactions to internal and external experience. Concordantly, halting automaticity through mindful processing of experience is thought to allow for self-regulation in goal pursuit (Brown et al. 2007a). This theory is in clear juxtaposition to operant models of human behavior that identify learning history and reinforcement as determined precursors of behavior (Skinner 1974).

Incorporating mindful awareness into parenting interactions can allow parents to stop and fundamentally shift their awareness in order to view their present-moment parenting experience within the context of the long-term relationship that they have with their child, as well as attend to their child's needs, while exercising self-regulation and wise choice in their actions. As in most domains, it is believed that acting primarily from automatic, selffocused, or hedonic motivations in parenting interactions will likely lead to less than optimal quality in parent-child relationships. When these principles have been applied to theories of parenting, essential distinctions have been made between parenting goals and motivations that are egoistic (self/parent-oriented) versus those that are child- and relationship-oriented (Dix and Branca 2003). When parents desire primarily to feel in control of their child (a parentoriented goal) without carefully taking their child's needs, wants, and feelings into perspective (i.e., they are not childoriented), they are not taking a relationship-oriented perspective. An example would be when, through ego concerns, habituated reactions, or hedonic motivations, parents impose forced behavioral compliance from their child through power assertion when it may not be necessary. Power-assertion, however, usually is at odds with the promotion of a warm and trusting relationship. When parents habitually seek control or seek the short-lived satisfaction of power-assertive control in their parenting, it may stem from either an inaccuracy in their affective forecasting about what will bring them the most long-term happiness or an inability to break the cycle of automaticity.

Our model of mindful parenting suggests that parents who can remain aware and accepting of their child's needs through using mindfulness practices can create a family context that allows for more enduring satisfaction and enjoyment in the parent-child relationship. This view of mindful parenting suggests that parents who either have a natural capacity for, or learn practices of mindfulness will be more likely to develop higher quality relationships with their children and more often avoid cycles of maladaptive parenting behavior that stem from automatic behaviors and 
hedonic motivations. This view is a substantial shift from operant behavioral models, and we believe that it is one that can allow for the cultivation of more open and trusting family relationships and parenting styles that will promote the healthy psychosocial development of the child (Baumrind 1989).

\section{Empirical Evidence on the Benefits of Mindfulness}

The scientific literatures on correlates of mindfulness and on the effects of mindfulness-based interventions have expanded considerably over the past several years (see Brown et al. 2007a, b). Western psychological theory and empirical evidence suggest mindfulness as both a psychological state and a construct that represents a dispositional tendency to exhibit mindfulness in everyday life (Baer et al. 2004; Bishop et al. 2004; Brown and Ryan 2003; Hayes and Feldman 2004). The practices of formal mindfulness meditation and bringing informal mindful awareness to activities of daily life are used to achieve the state of mindfulness, and the premise of many mindfulnessbased interventions is that a dispositional tendency to be mindful arises from or is increased by mindfulness practice. A growing body of evidence shows that when mindfulness is operationally defined as a dispositional tendency, it is related to psychological functioning in a variety of populations (Baer et al. 2006; Brown and Ryan 2003; Brown et al. 2007b; Chadwick et al. 2005), and is responsive to intervention (e.g., Carmody and Baer 2008).

As mentioned above, mindfulness has been defined as "a receptive attention to and awareness of present events and experience" (Brown and Ryan 2003) or "paying attention in a particular way: on purpose, in the present moment, nonjudgmentally" (Kabat-Zinn 1994, p. 4). These definitions reflect three core qualities of mindfulness: (a) present-centered attention and awareness; (b) intention or purposefulness, which highlights a motivational component to one's attention and behavior; and (c) attitude, which reflects how we attend, or the qualities that one brings to the act of paying attention, such as interest, curiosity, nonjudgment, acceptance, compassion, and receptiveness (Shapiro et al. 2006). These qualities are hypothesized to occur simultaneously in moment-to-moment experiences of mindfulness.

Mindfulness also has been characterized as comprising five mindfulness skills: "acting with awareness," "observing," "describing," "nonreactivity to inner experience," and "nonjudging of inner experience" (Baer et al. 2006; Carmody and Baer 2008) that represent a higher order mindfulness factor. The definition of mindfulness and how best to measure it is the subject of considerable debate in the field of psychology (Leary and Tate 2007), with some arguing that mindfulness represents a single quality of consciousness (i.e., present-centered awareness and attention) (Brown and Ryan 2003, 2004; Brown et al. $2007 \mathrm{a}, \mathrm{b})$ and others holding to a model that includes the five mindfulness skills (Baer 2007; Baer et al. 2006). Regardless of the number of dimensions used to operationally define mindfulness, studies evidence considerable consistency regarding significant correlates of the psychological construct of mindfulness. Mindfulness is associated with self-reported positive affect (Brown and Ryan 2003), less anxiety and depression (Baer et al. 2006, 2008; Brown and Ryan 2003), greater relationship satisfaction and less relationship stress (Barnes et al. 2007), and specific profiles of brain activity associated with greater emotion regulation during affect labeling (Creswell et al. 2007).

The individual mindfulness skills are also strongly related to other psychological processes. The "acting with awareness" dimension of the skills-based operational definition of mindfulness has a strong inverse relation with dissociation and absent-mindedness (Baer et al. 2006). "Observing" and "describing" are two mindfulness skills used to take account of your cognitions, affects, and somatic sensations as events in your present experience; observing is the intentional focusing of attention on stimuli and describing is putting those experiences into words. Observing may partially mediate the effects of mindfulness-based interventions on mindful attention and awareness (Baer et al. 2008). Describing is highly related to emotional intelligence and inversely related to alexithymia (Baer et al. 2006), suggesting an emotional awareness quality of this skill. The nonjudging aspect of mindfulness involves decentering from mental events and allowing thoughts to be "just thoughts" or affects to be "just feelings" instead of overidentifying with them. Thus, instead of being immediately reactive to sensed emotions or affects (e.g., anger, jealousy), emotional reactions are noticed with as little judgment as possible. Nonjudging includes acceptance of experience and thus can facilitate the ability to maintain direct contact with uncomfortable thoughts and feelings (Brown et al. 2007b) and it is inversely related to experiential avoidance and thought suppression (Baer et al. 2006). Nonreactivity is the self-regulation aspect of mindfulness. This skill is applied to self-regulation of reactivity to mental events, including social information processing. When individuals who report a greater tendency to bring mindfulness to experiences of daily life are faced with potentially threatening, yet ambiguous, behavior in others they are less likely to interpret the behavior as reflecting hostile intent, they exhibit a lower intensity of anger, and report less desire to retaliate (Heppner and Kernis 2007). 


\section{Mindfulness-Based Interventions}

Mindfulness training is increasingly employed in innovative therapies and interventions (Baer and Krietemeyer 2006) such as Mindfulness-Based Stress Reduction (MBSR; Kabat-Zinn 1982, 1990), Mindfulness-Based Cognitive Therapy (MBCT; Segal et al. 2002), Dialectical Behavior Therapy (DBT; Linehan 1993), and Acceptance and Commitment Therapy (ACT; Hayes 2004; Hayes et al. 1999). These and other secular mindfulness-based interventions have been shown in some studies to effectively reduce psychological and physiological reactivity to a variety of stressful life situations and chronic illnesses (Brantley 2005; Carlson et al. 2003; Kabat-Zinn 2003), treat anxiety (Roemer and Orsillo 2007), and decrease recurrence of depressive episodes (Ma and Teasdale 2004; Segal et al. 2002) and substance abuse relapse in adults (Bowen et al. 2006; Bowen et al. 2007), although more rigorous study designs and replication are needed to reach firm conclusions regarding their benefit. Overall, the empirical evidence regarding the outcomes of these interventions demonstrates the potential benefit of using them to break cycles of automatic behavior and cognitions in order to treat people suffering from a variety of disorders with a high likelihood of relapse (e.g., anxiety disorder, and substance abuse).

A small number of studies have begun to elucidate the biological and psychological mechanisms whereby the effects of mindfulness interventions are achieved (Bishop 2002; Davidson et al. 2003; Lazar 2005) and a metaanalysis of 21 studies of MBSR and MBSR-related interventions (Baer 2003) estimated a mean post-intervention weighted effect size of $d=0.59$. Mindful attention and awareness also appear to be modifiable through mindfulness-based intervention (Anderson et al. 2007; Jha et al. 2007), the effects of which may manifest through modification of attention subsystems (Jha et al. 2007) or, in some cases may be more evident in participants' awareness of the present moment than in basic attentional abilities (Anderson et al. 2007). Although the concept of mindfulness is intended to reflect processes directed toward one's internal and external experiences, the majority of interventions have used techniques within an individual treatment mode that emphasized attention to intrapersonal experiences (e.g., one's thoughts and feelings).

A key advancement in mindfulness interventions is an extension of mindfulness to interpersonal relationships including preventive interventions with nondistressed married and cohabiting couples (Mindfulness-Based Relationship Enhancement; MBRE; Carson et al. 2004). According to the developers of MBRE (Carson et al. 2006), the impetus for extending MBSR for use as a couples intervention was based: (a) on results of a meta-analytic review of 115 longitudinal studies of marriages that demonstrated that relationship functioning is improved by couples having good stress coping abilities (Karney and Bradbury 1995); and (b) on suggestions by relationship and marital therapy experts who endorse the importance of couples interventions that enhance acceptance and empathy and promote development of psychophysiologically soothing and self-expanding activities (e.g., Christensen and Jacobson 2000; Gottman 1993; Wenzel and Harvey 2001). Results from a randomized trial of MBRE provide evidence of its efficacy for improving psychological functioning, increasing stress coping efficacy, and increasing positive relationship characteristics (Carson et al. 2004). Mediational analyses indicated that improvements in relationship satisfaction due to MBRE were mediated by self-expansion (Carson et al. 2007). These results suggest that applying mindfulness-based interventions to influence interpersonal functioning within the context of a close relationship holds potential for shifting participant perceptions of themselves in relation to their close other in ways that promote an expanded awareness and close and loving relationship qualities. Applying similar techniques in other close relationships such as close parent-child relationships might provide similar benefit for the quality of the relationship.

\section{Mindfulness in Parenting}

A mindful approach to parenting has been suggested as one avenue for promoting secure attachment relationships (Siegel and Hartzell 2003) and we believe that the parentchild relationship is an ideal context in which to extend the concepts and practices of mindfulness. Our broad conceptualization of mindful parenting draws from Eastern and Western literatures on mindfulness mentioned above and builds upon a foundational account of how the daily practices of mindfulness are readily applicable to parenting (Kabat-Zinn and Kabat-Zinn 1997). The model of mindful parenting described here draws from the concepts and practices of psychological mindfulness (Baer et al. 2006; Brown and Ryan 2003), mindfulnessbased interventions (Kabat-Zinn 1994, 2003), and contemporary theoretical and empirical writings about parenting. It encompasses five dimensions of mindful parenting relevant to the parent-child relationship: (a) listening with full attention; (b) nonjudgmental acceptance of self and child; (c) emotional awareness of self and child; (d) self-regulation in the parenting relationship; and (e) compassion for self and child. Table 1 contains a list of these five dimensions and relates each mindful parenting dimension to parenting behaviors that are promoted by these attributes, skills, and practices. 
Table 1 Role of mindful parenting practices in parenting interactions

\begin{tabular}{|c|c|c|}
\hline $\begin{array}{l}\text { Mindful parenting } \\
\text { dimensions }\end{array}$ & $\begin{array}{l}\text { Effective parenting behaviors promoted through this } \\
\text { practice }\end{array}$ & Parenting behaviors decreased through this practice \\
\hline $\begin{array}{l}\text { Listening with full } \\
\text { attention }\end{array}$ & $\begin{array}{l}\text { - Correctly discern child's behavioral cues } \\
\text { - Accurately perceive child's verbal communication }\end{array}$ & $\begin{array}{l}\text { - Reduced use and influence of cognitive constructions } \\
\text { and expectations }\end{array}$ \\
\hline $\begin{array}{l}\text { Nonjudgmental } \\
\text { acceptance of self and } \\
\text { child }\end{array}$ & $\begin{array}{l}\text { - Healthy balance between child-oriented, parent- } \\
\text { oriented, and relationship-oriented goals } \\
\text { - Sense of parenting self-efficacy } \\
\text { - Appreciation for child's traits }\end{array}$ & $\begin{array}{l}\text { - Reduction in self-directed concerns } \\
\text { - Fewer unrealistic expectations of child's attributes }\end{array}$ \\
\hline $\begin{array}{l}\text { Emotional awareness of } \\
\text { self and child }\end{array}$ & $\begin{array}{l}\text { - Responsiveness to child's needs and emotions } \\
\text { - Greater accuracy in responsibility attributions }\end{array}$ & $\begin{array}{l}\text { - Less dismissing of child's emotions } \\
\text { - Less discipline that results from parent's strong negative } \\
\text { emotion (e.g., anger, disappointment, shame) }\end{array}$ \\
\hline $\begin{array}{l}\text { Self-regulation in the } \\
\text { parenting relationship }\end{array}$ & $\begin{array}{l}\text { - Emotion regulation in the parenting context } \\
\text { - Parenting in accordance with goals and values }\end{array}$ & $\begin{array}{l}\text { - Less overreactive/“automatic" discipline } \\
\text { - Less dependence on child's emotions }\end{array}$ \\
\hline $\begin{array}{l}\text { Compassion for self and } \\
\text { child }\end{array}$ & $\begin{array}{l}\text { - Positive affection in the parent-child relationship } \\
\text { - More forgiving view of own parenting efforts }\end{array}$ & $\begin{array}{l}\text { - Less negative affect displayed in the parent-child } \\
\text { relationship } \\
\text { - Less self-blame when parenting goals are not achieved }\end{array}$ \\
\hline
\end{tabular}

\section{Dimensions of Mindful Parenting}

\section{Listening with Full Attention}

Clear attention and receptive awareness to the experiences of the present moment are central aspects of mindfulness (Baer et al. 2006; Brown and Ryan 2003) and also to effective parenting. Our model of mindful parenting pairs full attention with listening because it is by directing their full attention to their child that parents convey that they are truly listening to their child. This dimension of mindful parenting combines listening with a quality of focused attention and awareness that goes beyond simply hearing words that are said. In early childhood, parental sensitive attention is often directed to cries or behaviors that signal physical or emotional discomfort. Being fully attentive and developing an internal representation of the child's perspective are important when parents and children are involved in direct interactions (Ainsworth et al. 1978; Maccoby and Martin 1983) and serve a protective function for young children who require the watchful eyes of an attachment figure to keep them from danger (Fonagy and Target 1997; Siegel 2001).

Later, parents who are mindful are sensitive both to the content of conversations as well as their child's tone of voice, facial expressions, and body language, effectively using these cues to successfully detect their child's needs or intended meaning. When children reach adolescence, listening with full attention may be particularly important because parents cannot physically monitor most of their youth's behavior and the information that parents gather is likely to be through verbal report rather than direct observation (Smetana et al. 2006). By bringing their full attention to these interactions parents may perceive their adolescents' thoughts and feelings more accurately, which in turn, may reduce conflict and disagreement (Hastings and Grusec 1998) and promote more self-disclosure by the adolescent (Smetana et al. 2006).

\section{Nonjudgmental Acceptance of Self and Child}

Mindful parenting involves being consciously attentive to the attributions and expectations one is making that may skew perceptions of parenting interactions. The human mind is intricately adept at making subconscious judgments (Bargh and Chartrand 1999) and parental perceptions of their youth's attributes and competence influence their expectations, values, and ultimately their child's behavior (Jacobs and Eccles 1992; Jacobs et al. 2005). Through their own behaviors and verbal messages, parents communicate their beliefs about their child's attributes and competencies and these communications may be biased by parents' own desires for the attributes they want their child to possess, even if those are not realistic for that child (Goodnow 1985).

Mindful parenting involves a nonjudgmental acceptance of the traits, attributes, and behaviors of self and child. Acceptance in this regard, however, does not mean a resigned acceptance that relinquishes responsibility for enacting discipline and guidance when necessary, rather it means an acceptance of what is happening in the present moment that is based on clear awareness and attention and gives rise to fuller understanding. It also means acceptance of the notions that there will be struggles in parent-child relationships, that parenting can be very challenging at times, and that growing up in today's world can be difficult for children. Acceptance means recognizing that these challenges we confront and the mistakes we make are all a 
healthy part of life. However, acceptance does not mean approving of child behavior if it does not meet parental expectations. Instead, mindful parents convey their fundamental acceptance of their child and also provide clear standards and expectations for their child's behavior that are appropriate for both the cultural context and the child's developmental level.

\section{Emotional Awareness of Self and Child}

Mindfulness theories emphasize individuals' capacities for focusing attention on their internal states of being such as cognitions and emotions. In our model of mindful parenting, we emphasize parents' capacity for awareness of emotions within themselves and their child. Strong emotions can trigger automatic evaluative processes (Bargh and Williams 2007) that in turn, lead individuals to enact specific behaviors. To truly be able to listen with full attention and to do so nonjudgmentally requires parents to also have the capacity for correctly identifying emotions within themselves and their child. Parents experience intense negative and positive affect during parenting and virtually all aspects of parenting are influenced by parents' affective activation, engagement, and regulation (Dix 1991). Emotional awareness is a foundation of mindful parenting because strong emotions have a powerful influence on igniting automatic cognitive processes and behaviors that are likely to undermine parenting practices. If parents are able to identify both their own and their child's emotions by bringing a mindful awareness to the interaction, they will be able to make conscious choices about how to respond, rather than reacting automatically to these experiences. Mindful parenting also reflects parents' greater willingness and ability to endure strong emotions through decentering (noting that feelings are just feelings) thus allowing them to be more fully present with their child.

\section{Self-Regulation in the Parenting Relationship}

Beyond the elements of full attention and emotional awareness, mindful parenting implies a certain degree of self-regulation. Mindfulness theorists have cautioned against confounding mindfulness with self-control and selfregulation (Brown et al. 2007a). Our view, however, is that mindful parenting necessarily requires self-regulation in the relationship context. Mindful parenting involves low reactivity to normative child behavior achieved through autonomous self-control in the service of exercising parenting behavior that is in accordance with parenting values and goals. Mindful parenting does not imply that the impulse to display negative affect, anger, or hostility is not felt, but mindful parenting involves pausing before reacting in parenting interactions in order to exercise greater selfregulation and choice in the selection of parenting practices. The ways in which parents respond to their child's emotions and express their own emotions have an important socializing effect (Eisenberg et al. 1998). Parents who are tolerant and supportive of their child's emotional displays and do not dismiss or meet their child's displays of negative affect with their own negative affect promote more emotionally and socially competent youth (Eisenberg et al. 1998; Katz et al. 1999). Mindful parenting may also promote parenting practices such as teaching children how to label, express, and talk about their feelings, which can promote youth's own self-regulation abilities (Gottman et al. 1997).

\section{Compassion for Self and Child}

In addition to an open and accepting stance, mindful parenting includes an active projection of empathic concern for one's child and for oneself as a parent. Compassion is defined as an emotion representing the "desire to alleviate suffering" (Lazarus and Lazarus 1994). Through compassion for one's child, a mindful parent will feel a desire to meet appropriate child needs and comfort distress that the child might be feeling. Children of mindful parents may feel a greater sense of positive affection and support from their parents. Self-compassion is partially comprised of a sense of common humanity (Neff 2003), which applied in parenting may allow parents to take a less harsh, more forgiving view of their own parenting efforts. Self-compassion in parenting entails avoiding self-blame when parenting goals are not achieved, which may allow reengagement in pursuit of parenting goals. It also may reduce the social evaluative threat that may be felt by parents who feel judged by others with regards to their own parenting behavior or their child's behavior in public social contexts. Parental self-evaluations can have considerable influence on parenting (Teti and Gelfand 1991) and on parent-child interactions. Parents who believe they are competent and efficacious interact with their children in a way that promotes effective developmental outcomes (Coleman and Karraker 2003). Parents, however, are often their own harshest critics. A mindful approach may lead to greater acceptance of one's efforts in the process rather than a focus on specific outcomes of parenting.

\section{Mindful Parenting and Parent-Child Relationships}

Our model of mindful parenting comprises the five interrelated elements described above, but we should also note that mindful parenting is an approach to parenting that is reflected in qualitatively different intrapsychic and 
interpersonal processes within the dynamic parent-child relationship. When parents bring the practices of mindful parenting to parent-child interactions, they can cultivate an enhanced capacity for parenting calmly, with greater consistency, and in greater accordance with their goals and values, while engendering a warm and nurturing affective tenor in the parent-child relationship. Mindful parenting will also contribute to a more generally positive parentchild relationship (e.g., more positive and less negative affect, greater trust and emotional sharing), to greater flexibility and responsiveness within the dynamic exchanges of parent-child relations, to a decreased level of parenting stress, to a wiser use of parenting strategies, and to greater youth well-being. We also believe that a mindful approach to parenting can disrupt the destructive cycle of negativity and disengagement that can become entrenched and almost "automatic" for some parent-child dyads (Dishion et al. 2003). Finally, we view mindfulness and mindful parenting as potential psychological resources in the stress and coping process (Lazarus and Folkman 1984; Folkman 1997), allowing parents to exercise more adaptive coping and therefore avoid the potentially disruptive influence of contextual-, family-, and parenting-related stress appraisals on their own psychological well-being and their parenting. Although we view these qualities as important for parenting across the lifespan, the focus of our recent work has been on the particular implications of mindful parenting for parent and child successful adaptation across the developmental transition to adolescence.
Figure 1 depicts our model of the hypothesized influence of mindful parenting on key aspects of the parent-child relationship (i.e., parenting, parental well-being, child management practices, and parent-child affection) that in turn have been shown to affect both positive and problem youth outcomes.

\section{The Dynamic Context of Parent-Adolescent Relationships}

Although there is considerable stability in the quality of parent-child relationships across the transition to adolescence, there are also several notable changes (Collins and Laursen 2004). During adolescence, parents and youth spend less time together (Larson et al. 1996), report a decline in feelings of closeness (Laursen and Williams 1997), and an increase in the intensity of affect associated with their conflicts (Laursen et al. 1998). Adolescents' ability to think in the abstract increases and they may argue more with their parents (Smetana and Asquith 1994). Declines in expressions of positive affect and increases in negative affect show linear trajectories from early to midadolescence with a slight reversal in late adolescence; yet, levels do not return to those seen in early adolescence (Kim et al. 2001). Moreover, it appears that these interactions are reciprocated (Conger and Ge 1999) and become mutually reinforcing; levels of escalating negativity from one person predict subsequent escalation in negativity from the other (Conger and Ge 1999; Kim et al. 2001). All of these

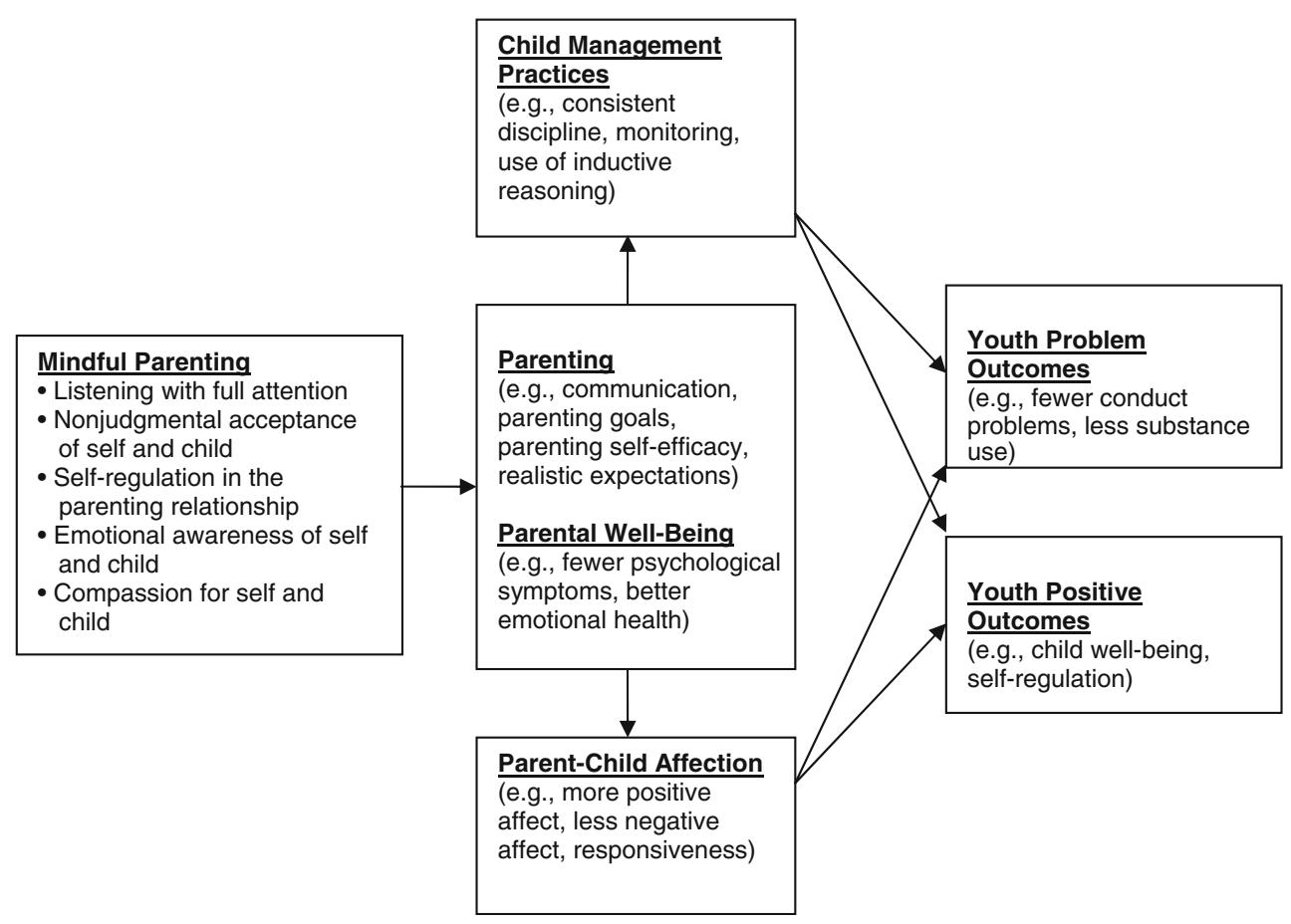

Fig. 1 Mindful parenting, parent-child relationships, and youth outcomes 
changes in adolescents' expression of their affect and cognitions, along with an increased quest for autonomy from their parents, pose a challenge that parents may appraise as stressful (Small et al. 1988).

Dynamic models of parenting propose bilateral, transactional processes of adaptation in which parents act to influence youth, youth act in response, which in turn influences parents' behavior and how they interact with their youth in the future (Maccoby 2003). Additionally, contemporary models of parenting attend to developmental changes in parents' life roles and experiences (Collins et al. 2000). For example, midlife, a period of the lifespan when adults are often parenting adolescents, is also often a time of increased family financial strain, work-related stress, and identity issues for parents, which are strongly related to adult's positive and negative affect (Mroczek 2004). Parent's self-image and their levels of satisfaction with work and marriage are related to levels of negativity in parentadolescent interactions (Collins 1995). Mindful parenting may enhance parents' abilities to successfully navigate their children's affective, cognitive, and behavioral changes during adolescence, as well as adapt to their own developmental changes.

Navigating the Changes in Parent-Adolescent

Relationships Through Mindful Parenting

Our model of mindful parenting acknowledges that during the period of developmental change in parent-adolescent relationships both parent and youth are agentic partners (Kuczynski and Parkin 2007). However, it also emphasizes behaviors and characteristics of the parent, rather than the youth, that are central to effectively and flexibly renegotiating aspects of the relationship in a way that maintains two of its critical functions: closeness and socialization (Dix and Branca 2003; Maccoby 2007). Parent-adolescent relationships are partly cognitive constructions that are created over years of interactions, and partners often experience their relationship through these cognitive filters (Lollis and Kuczynski 1997; Main et al. 1985) rather than through present experience. For example, parental expectations for and attributions about their youth's behavior derive not only from a pattern of interactions at an earlier stage of development, but also from anticipated futureoriented socialization goals (Dawber and Kuczynski 1999) and from global expectations for development, such as what adolescence will be like (Buchanan 2003). Parents may also interpret youth behavior through a bias of selfinterest and ego-involvement (e.g., youth behavior reflects strongly on parent as a person), or with judgments and attributions about the child's intentions for behaving that way (Dix et al. 1986).
Parent's automatic cognitive processes may be triggered by something their youth says or does, which in turn elicits strong emotional and behavioral reactions from the parent (Kerr and Stattin 2003) which may include overreactive, harsh discipline strategies (Dix et al. 1986; Leung and Slep 2006). Consequently, adolescents who developmentally face more challenges in regulating negative emotions and managing emotional lability (Larson et al. 1996) may react strongly and escalate the cycle of negativity. Such transactional emotion dynamics are central theoretical elements of models of the role of parenting and family functioning in the development of problem behaviors (e.g., Patterson et al. 1992). Parents who bring a mindful parenting approach to such a situation may listen intently with nonjudgmental acceptance, not focus on memories and/or future expectations to interpret what is happening in the moment, show low emotional reactivity and thereby maintain parentyouth closeness, support parental monitoring and use the situation to help socialize appropriate behavior. This kind of interaction is likely to yield strong adolescent-parent connections that contribute to a mutually responsive orientation (Maccoby 2007).

\section{Applications of Mindfulness in Parenting Interventions}

The first significant discussion of the application of mindfulness to parenting was published by Myla and Jon Kabat-Zinn (Kabat-Zinn and Kabat-Zinn 1997). This pioneering work described their recommendations for extending and integrating into family life the practices of mindfulness taught in the Stress Reduction Clinic at the University of Massachusetts Medical Center. The KabatZinns suggested a daily practice of mindful parenting that should take into account the changing developmental needs of the child from birth through young adulthood. A next step was taken by Dumas (2005) in a ground-breaking paper that described mindfulness training as one avenue for parents to break the "automaticity" of maladaptive parenting interactions. Dumas developed mindfulness-based parent training as a psychotherapeutic model for a therapist to work individually with parents to help them examine their "automatized transactional procedures" (ATPs) that are described as "... transactional, relationship-specific ways of coping that are performed with little conscious awareness, stable and highly resistant to change" (Dumas 2005). In this intervention model, ineffective ATPs exacerbate conflict in families and are reinforced by negative affect. Dumas (2005) suggests mindfulness training as a mechanism whereby parents might "consider their own and their child's behavior nonjudgmentally, to distance themselves from negative emotions, and to develop parenting goals that are accompanied by motivated action plans" for 
adaptive coping that will become automatic with practice (p. 780). Our model of mindful parenting includes some similar components, including distancing from negative affect and a focus on reducing automatic reactions through mindfulness practice.

Although mindful parenting is growing in appeal as a focus for clinical practice with families, there have been very few published studies that evaluated the effects of mindful parenting programs and, to our knowledge, all have been done in treatment settings. In the first, an intensive measurement burst, multiple-baseline study was conducted with three mothers of children with autism who participated in an individually delivered, 12-week mindful parenting course (Singh et al. 2006). A pre- to post-intervention increase in mothers' mindful parenting was associated with decreases in child aggression, noncompliance, and self-injury. Notably, mothers' satisfaction with their parenting skills and with their parenting interactions increased markedly when they began using mindfulness on a daily basis and remained high (Singh et al. 2006).

The second, a small randomized controlled trial of the parents under pressure (PUP) intervention, was conducted with 64 Australian families with a parent on methadone maintenance and children age 2-8 years (Dawe and Harnett 2007). The PUP program is an intensive 10-session, home-based intervention that incorporates mindfulness skills-training designed to improve parent affect regulation during parent-child play and includes elements of mindfulness-based relapse prevention (Witkiewitz et al. 2005) to reduce the likelihood of substance abuse relapse. PUP participants showed significant improvements in family functioning compared to controls, including a reduction in child abuse potential, that were maintained at three-month and six-month follow-up assessments (Dawe and Harnett 2007). This study provides a model for combining individual mindfulness-based treatment with mindful parenting practices for a selected population. The only study of a group-based (vs. individually-delivered) mindful parenting intervention reported in the literature involved delivery of a previously unevaluated 12 -week mindful parenting program (Placone-Willey 2002) to a convenience sample of 12 recently divorced parents of preschool age children with no comparison group (Altmaier and Maloney 2007). Results indicated a significant pre- to post-intervention increase in state mindfulness, but no changes were found on observational ratings of parent-child relationships.

The results of these three studies suggest that mindful parenting interventions may have potential for improving parenting satisfaction, family functioning, and mindfulness. However, it is not certain that the effects obtained in these studies are due to the mindfulness component or are merely the effects of quality parenting treatment based more on an operant model. It is clear that there is a need for considerable additional research and examination of the mechanisms of action of mindful parenting interventions.

\section{Mindful Parenting as a Model for Preventive Intervention}

In spite of the substantial interest in applying mindfulness models to family and parenting research, it is noteworthy that there had been no applications to evidence-based, family-focused preventive interventions. As we considered the most effective way to support the qualities of mindful parenting, our research group decided that rather than develop an entirely new intervention, we would supplement a high-quality existing model. After review of effective programs, we chose to adapt the Strengthening Families Program: For Parents and Youth 10-14 (SFP; Molgaard et al. 2001), an existing, empirically validated, seven-session, universal family preventive intervention. We elected this strategy because of the strong empirical evidence that SFP improves parenting practices (Redmond et al. 1999; Spoth et al. 1998) and delays the onset and escalation of alcohol and other drug use in adolescence (Spoth et al. 1999, 2001, 2004, 2006) and because the content of SFP already implicitly contained many of the underlying principles we have outlined here in our model of mindful parenting. Our task was to make these implicit messages more explicit by adding mindfulness practice activities and by more clearly reinforcing principles of mindfulness by altering some of the language used throughout the sessions. With assistance from the program developer, Virgina Molgaard, we created a revised curriculum (MSFP: Mindfulness-enhanced SFP) by infusing concepts and practices related to mindfulness and mindful parenting throughout the standard program's seven parent sessions.

Our program of research has taken several steps to evaluate and refine the mindful parenting intervention activities. Our first step was to explore the feasibility of incorporating mindfulness and mindful parenting activities into SFP and to gauge the acceptability of the new content to parent participants. Overall, results from an initial pilot project with a single intervention group (Duncan et al. 2009) suggested that it was feasible to implement the new mindfulness and mindful parenting activities and that parents found the additional mindfulness components to be both acceptable and useful. Observation of sessions and feedback from parents also suggested that the curriculum could be improved by condensing didactic activities that took too long to deliver, shortening several mindfulness activities, and conducting experiential mindfulness activities with periods of silence rather than with verbal guidance throughout. Second, we further revised the curriculum to 
enhance acceptability and to include an additional explicit emphasis on mindfulness and mindful parenting throughout each curriculum activity before conducting a second pilot study.

Next, we tested the revised curriculum in a pilot randomized controlled trial conducted in three Pennsylvania school districts (Coatsworth et al. 2009). In this trial, a sample of families of 5 th-7th grade students from three school districts were randomly assigned to MSFP, the original SFP program, or a wait-list control group and completed pre- and post-intervention self-report assessments. Effect size estimates for intervention outcomes on an array of parenting and family functioning variables are reported elsewhere (Coatsworth et al. 2009). Notable results demonstrated significantly stronger intervention effects of the MSFP program compared to standard SFP program or the waitlist control conditions on mindful parenting (assessed with the Interpersonal Mindfulness in Parenting Scale; Duncan 2007), parent-youth relationship quality, and reports of parental mental health and wellbeing. Results of the pilot efficacy trial show promise for the value of a mindful parenting approach for enhancing the efficacy of universal prevention with rural families of young teens.

The format of all MSFP intervention sessions is similar to the original SFP sessions. The content of the youth and family sessions is identical; only the content in the parenting sessions has been altered. On average we added two new activities to each session. New activities were designed to teach parents the skills of mindful parenting that would enhance their abilities to: (a) pay close attention and listen carefully to their children during moment-tomoment parenting interactions; (b) become more aware of their own emotional states and the emotional states of their youth; (c) become more likely to adopt an accepting, nonjudgmental attitude when interacting with their youth; (d) regulate their own affective reactions during their interactions with their youth; and (e) adopt a stance of empathy and compassion toward their children and themselves; and to do all of these things in the context of a fundamental shift in their perspective of what it means to truly be present with their children with a focus on their desire to have an authentic and caring relationship.

\section{Listening with Full Attention}

During each MSFP intervention session, parents are taught how to focus their attention through brief mindfulness practices. In order to assure the secular nature of our mindfulness practice activities, we have defined "reflections" as short activities in which parents are asked to sit comfortably, close their eyes if they wish, and focus their attention on some aspect of their present experience, for example their breathing or thoughts they are having about themselves or their child. These reflections draw from meditation practices and they are designed to increase mindful attention and awareness; they are reinforced throughout the MSFP sessions, particularly during activities in which the importance of truly listening to adolescents is discussed. Within the sessions that focus on listening, parents are taught behaviors that characterize good versus poor communication (e.g., attention and following versus ignoring, advice giving, or judging), how youth might feel when parents are not listening to them, how parents can listen for youths' underlying affect in what they are saying, how parents can monitor their own feelings when youth are not talking, and how parents can avoid forcing communication when they feel frustrated by youth lack of disclosure. Parents are taught that clear attention and awareness is an essential aspect of good listening and effective communication with their adolescents. Because it is not possible for parents to listen with full attention to their youth at all times, parents discuss when it is difficult for them to do this and how they can let their youth know that they want to hear what she has to say later, when they have the opportunity to pay attention fully.

\section{Nonjudgmental Acceptance of Self and Child}

During MSFP, parents experience a variety of activities in which they reflect on the commonalities and differences between themselves and their youth. They are asked to focus on their child's unique needs and characteristics. They reflect on the kinds of attributions they make about themselves and their child and the source of those attributions. For example, parents learn to self-monitor whether and when their sense of public self-consciousness creates expectations against which they judge their own and their youths' behaviors. Parents are also asked to reflect on the extent to which some of their parenting goals are childcentered or parent-centered (Dix and Branca 2003). Parents are asked to practice bringing an open, nonjudgmental, and accepting stance to their parenting interactions.

\section{Emotional Awareness of Self and Child}

The MSFP intervention helps build awareness of the emotions of parenting by teaching parents how to recognize and label their moment-to-moment affective experiences. Parents are asked to practice noticing the "comfortable" and "uncomfortable" emotions of parenting. They reflect on the positive and negative affect that they and their child experience and express during parenting interactions and how their moods influence one another. These activities also help parents identify situations with their teens in which they are more likely to 
experience uncomfortable emotions that can escalate into interactions filled with angry and hurtful words and actions. Teaching parents how to increase their attention and awareness of their own emotional experiences and of their youths' emotions, even those that are less overtly expressed, is seen as an initial step to altering escalating cycles of negative affect and behavior that may be triggered "automatically."

\section{Self-Regulation in the Parenting Relationship}

In MSFP, parents are taught mindfulness practices that target their automatic cognitive-affective reactions to escalating emotions and their physiological stress reactivity. Parents are taught brief breath awareness activities and they learn that paying attention to the breath can have a calming effect. They are given the simple phrase "Stop, Be Calm, Be Present" to use when they become aware of the need to self-regulate and focus on their broader parenting goals instead of reacting automatically out of immediate desires. MSFP activities are designed to allow parents to practice bringing their consciousness to those parent-child interactions that elicit strong emotions that can trigger automatic behavioral reactions and learn to work with those reactions with mindfulness.

\section{Compassion for Self and Child}

Throughout MSFP, we incorporate themes of caring and compassion. The original SFP curriculum contains a central theme of balancing "Love and Limits," or warmth and discipline (Molgaard et al. 2001). We expanded upon this theme by infusing the curriculum with brief reflections designed to bring about greater compassion for the difficulties of being an adolescent and greater self-compassion for the difficulties of being the parent of an adolescent. We adapted these reflections from loving-kindness meditation practices (Salzberg 1995) that have been found to promote daily positive emotions including love, joy, and contentment (Fredrickson et al. 2008). Parents are also encouraged to identify aspects of their parenting that they feel good about and to avoid judging themselves harshly when they do not meet their own goals.

\section{Future Directions}

\section{Mindful Parenting Intervention Research}

Prevention research can provide experimental studies of whether improving mindful parenting through intervention can achieve the goal of substantially improving parentchild relationships. Empirical tests of mindful parenting interventions are in an early stage and there is also considerable work yet to be done in the areas of theory, research, and application of mindfulness in parenting. On the one hand, models of mindfulness in parenting, such as the one presented here, are needed to move the field forward. Our model drew from Eastern and Western teachings on mindfulness and compassion to identify five dimensions that could be applied to parent-child interactions. Mindfulness theories describe other dimensions that might plausibly fit into an alternative model of mindful parenting. More, not fewer, theoretical models will ultimately help to stimulate empirical and applied science. These theoretical models will not only have to describe the specific dimensions of mindful parenting they are proposing, but also indicate what kinds of positive and negative developmental outcomes might result from such an approach. Further, such models should convey the interpersonal and/or intrapersonal mechanisms (mediators) by which mindful parenting relates to human development. A second step in this research process is establishing sound measurement of the proposed models. Finally, translating the models into interventions with a clearly defined set of intervention activities and guidelines and testing their efficacy in rigorous clinical trials will be necessary to confirm or disconfirm empirical claims. Central to these trials will be carefully planned evaluations that can provide insights into how a mindful parenting intervention produces its effects. Given that intervention science currently has a broad number of empirically validated interventions to alter parenting and family processes (see Cowan et al. 1998; Kumpfer and Alvarado 2003; Taylor and Biglan 1998), it may require well-designed comparative studies with carefully chosen comparison interventions that can control for some processes while yielding information about the value added of a mindful parenting intervention. Added value may be found in enhanced effects in certain areas (e.g., stronger effects for parenting practices or parent-child relationship quality), or in a wider range of effects on proximal and distal outcomes (e.g., parental stress reduction and well-being, youth intrapersonal processes). Early tests of intervention effects should test a broad array of plausible mechanisms and outcomes in order to expand our knowledge base and help refine our theoretical models.

We have adopted some of these guidelines within our own research program and the next phase of our study of MSFP will involve a large-scale randomized trial to test program efficacy and to examine the additive benefits for parenting, parent-youth relations, youth outcomes, and parental psychological well-being. We have proposed to test our intervention using a three-arm research design that includes MSFP, standard SFP, and a limited intervention control condition. This design allows us to test specific hypotheses (represented in our model in Fig. 1) about 
whether enhancing family-focused prevention with mindful parenting training provides added value beyond more traditional models of parenting. We have hypothesized that MSFP will produce enhanced effects on parenting practices and especially on parent-youth affective relations. We expect these enhanced effects on parenting practices will mediate effects on youth outcomes such as conduct problems and substance use. Moreover, we expect the practice of mindfulness applied to parenting by our adult participants to produce some salutogenic effects on parent psychological well-being and physiological stress reactivity in the parenting context.

\section{Extending Mindful Parenting to Other Developmental} Stages

In addition to our work on MSFP, we are collaborating with practitioners to develop and assess mindful parenting programs for other stages of parenting. MBSR (Kabat-Zinn 1982, 1990) has been combined with traditional childbirth education in a theory- and evidence-based program model that teaches expectant parents how to cope more adaptively with stress during pregnancy, childbirth, and early parenting, while cultivating mindfulness and mindful parenting (Mindfulness-Based Childbirth and Parenting education; MBCP; Bardacke 1998-2009). For early childhood, The Circle of Security intervention (Marvin et al. 2000) provides a program model for working with parents of toddlers on themes of attachment that are relevant for mindful and compassionate parenting during this developmental stage. The MSFP program covers the transition to adolescence (ages 10-14) and our mindful parenting activities could be extended to middle childhood, creating comprehensive coverage of developmentally appropriate mindful parenting intervention across childhood.

\section{Conclusion}

This paper has described our efforts to-date to extend the conceptualization and application of mindfulness to the interpersonal domain of parent-child relationships and integrate mindfulness activities into a universal family preventive intervention. Our model of mindful parenting suggests that the quality of parent-child relationships will be improved by promoting parents' ability to bring a present-moment awareness to their parenting that includes listening with full attention, bringing emotional awareness and nonjudgmental acceptance to their parenting interactions, and practicing self-regulation and compassion in their parenting relationships. Mindful parenting is not simply a new skill-set; it is a new epistemological orientation. We believe that parents who adopt a mindfulness orientation for their parenting and regularly engage in mindful parenting practices will undergo a fundamental shift in their ability and willingness to truly be present with the constantly growing and changing nature of their child and their relationship with their child. In this way, parents can be freed from the egoistic, habitual, and hedonic motivations that may lead them astray in their parenting practices and cultivate a parenting perspective that incorporates a long view of the enduring nature of the relationship with the use of wisdom in selecting appropriate parenting responses in the moment.

Acknowledgments Preparation of this paper was supported by the National Institute on Drug Abuse through a predoctoral training fellowship (T32 DA 017629) and by the National Center for Complementary and Alternative Medicine through a postdoctoral fellowship (T32 AT003997) to the first author. The insightful contributions of Virginia Molgaard, Elaine Berrena, Christa Turksma, and Robert Nix during the development of the Mindfulness-enhanced Strengthening Families Program curriculum are gratefully acknowledged and we wish to thank the Pennsylvania families who gave us valuable feedback on how to teach the practices of mindful parenting. Support for the MSFP pilot studies was provided by the Penn State Children, Youth, and Families Consortium. Our deepest appreciation is extended to Myla and Jon Kabat-Zinn for their teachings on mindful parenting and for providing the inspiration for this work.

Open Access This article is distributed under the terms of the Creative Commons Attribution Noncommercial License which permits any noncommercial use, distribution, and reproduction in any medium, provided the original author(s) and source are credited.

\section{References}

Ainsworth, M. D. S., Blehar, M. C., Waters, E., \& Wall, S. (1978). Patterns of attachment. Hillsdale, NJ: Erlbaum.

Altmaier, E., \& Maloney, R. (2007). An initial evaluation of a mindful parenting program. Journal of Clinical Psychology, 63(12), 1231-1238. doi:10.1002/jclp.20395.

Anderson, N. D., Lau, M. A., Segal, Z., \& Bishop, S. R. (2007). Mindfulness-based stress reduction and attentional control. Clinical Psychology \& Psychotherapy, 14, 449-463. doi: 10.1002/cpp.544.

Baer, R. A. (2003). Mindfulness training as a clinical intervention: A conceptual and empirical review. Clinical Psychology: Science and Practice, 10, 125-143. doi:10.1093/clipsy/bpg015.

Baer, R. A. (2007). Mindfulness, assessment, and transdiagnostic processes. Psychological Inquiry, 18(4), 238-242.

Baer, R. A., \& Krietemeyer, J. (2006). Overview of mindfulness- and acceptance-based treatment approaches. In R. A. Baer (Ed.), Mindfulness-based treatment approaches (pp. 3-27). Burlington, MA: Elsevier Academic Press.

Baer, R. A., Smith, G. T., \& Allen, K. B. (2004). Assessment of mindfulness by self-report: The Kentucky Inventory of Mindfulness Skills. Assessment of Mindfulness, 11, 191-206. doi: 10.1177/1073191104268029.

Baer, R. A., Smith, G. T., Hopkins, J., Krietemeyer, J., \& Toney, L. (2006). Using self-report assessment methods to explore facets of mindfulness. Assessment, 13, 27-45. doi:10.1177/107319 1105283504. 
Baer, R. A., Smith, G. T., Lykins, E., Button, D., Krietemeyer, J., Sauer, S., et al. (2008). Construct validity of the five facet mindfulness questionnaire in meditating and nonmeditating samples. Assessment, 15, 242-329. doi:10.1177/107319110 7313003.

Bardacke, N. (1998-2009). Mindfulness-based childbirth and parenting education curriculum manual. Oakland, CA: Mindful Birthing and Parenting Foundation.

Bargh, J. A., \& Chartrand, T. L. (1999). The unbearable automaticity of being. The American Psychologist, 54, 462-479. doi:10.1037/ 0003-066X.54.7.462.

Bargh, J. A., \& Williams, L. E. (2007). The nonconscious regulation of emotion. In J. J. Gross (Ed.), Handbook of emotion regulation (pp. 429-445). New York: Guilford Press.

Barnes, S., Brown, K. W., Krusemark, E., Campbell, W. K., \& Rogge, R. D. (2007). The role of mindfulness in romantic relationship satisfaction and responses to relationship stress. Journal of Marital and Family Therapy, 33(4), 482-500. doi:10.1111/ j.1752-0606.2007.00033.x.

Baumrind, D. (1989). Rearing competent children. In W. Damon (Ed.), Child development today and tomorrow (pp. 349-378). San Francisco: Jossey-Bass.

Bishop, S. R. (2002). What do we really know about MindfulnessBased Stress Reduction? Psychosomatic Medicine, 64, 71-84.

Bishop, S. R., Lau, M., Shapiro, S., Carlson, L., Anderson, N. D., Carmody, J., et al. (2004). Mindfulness: A proposed operational definition. Clinical Psychology: Science and Practice, 11, 230241. doi:10.1093/clipsy/bph077.

Bowen, S., Witkiewitz, K., Dillworth, T. M., Chawla, N., Simpson, T. L., Ostafin, B. D., et al. (2006). Mindfulness meditation and substance use in an incarcerated population. Psychology of Addictive Behaviors, 20, 343-347. doi:10.1037/0893-164X. 20.3.343.

Bowen, S., Witkiewitz, K., Dillworth, T. M., \& Marlatt, G. A. (2007). The role of thought suppression in the relationship between mindfulness mediation and alcohol use. Addictive Behaviors, 32, 2324-2328. doi:10.1016/j.addbeh.2007.01.025.

Brantley, J. (2005). Mindfulness-based stress reduction. In S. M. Orsillo \& L. Roemer (Eds.), Acceptance and mindfulness-based approaches to anxiety: Conceptualization and treatment. Series in anxiety and related disorders (pp. 131-145). New York, NY: Springer.

Brown, K. W., \& Ryan, R. M. (2003). The benefits of being present: Mindfulness and its role in psychological well-being. Journal of Personality and Social Psychology, 84, 822-848. doi: 10.1037/0022-3514.84.4.822.

Brown, K. W., \& Ryan, R. M. (2004). Perils and promise in defining and measuring mindfulness: Observations from experience. Clinical Psychology: Science and Practice, 11, 242-248. doi: 10.1093/clipsy/bph078.

Brown, K. W., Ryan, R. M., \& Creswell, J. D. (2007a). Mindfulness: Theoretical foundations and evidence for its salutary effects. Psychological Inquiry, 18(4), 211-237.

Brown, K. W., Ryan, R. M., \& Creswell, J. D. (2007b). Addressing fundamental questions about mindfulness. Psychological Inquiry, 18(4), 272-281.

Buchanan, C. M. (2003). Mother's generalized beliefs about adolescents: Links to expectations for a specific child. The Journal of Early Adolescence, 23, 29-50. doi:10.1177/0272431602239129.

Carlson, L. E., Speca, M., Patel, K. D., \& Goodey, E. (2003). Mindfulness-based stress reduction in relation to quality of life, mood, symptoms of stress, and immune parameters in breast and prostate cancer outpatients. Psychosomatic Medicine, 65, 571581. doi:10.1097/01.PSY.0000074003.35911.41.

Carmody, J., \& Baer, R. A. (2008). Relationships between mindfulness practice and levels of mindfulness, medical and psychological symptoms and well-being in a mindfulness-based stress reduction program. Journal of Behavioral Medicine, 31, 23-33. doi:10.1007/s10865-007-9130-7.

Carson, J. W., Carson, K. M., Gil, K. M., \& Baucom, D. H. (2004). Mindfulness-based relationship enhancement. Behavior Therapy, 35, 471-494. doi:10.1016/S0005-7894(04)80028-5.

Carson, J. W., Carson, K. M., Gil, K. M., \& Baucom, D. H. (2006). Mindfulness-based relationship enhancement in couples. In R. A. Baer (Ed.), Mindfulness-based treatment approaches: Clinician's guide to evidence base and applications (pp. 309-331). Amsterdam: Elsevier.

Carson, J. W., Carson, K. M., Gil, K. M., \& Baucom, D. H. (2007). Self-expansion as a mediator of relationship improvements in a mindfulness intervention. Journal of Marital and Family Therapy, 33, 517-528. doi:10.1111/j.1752-0606.2007.00035.x.

Chadwick, P., Hember, M., Mead, S., Lilley, B., \& Dagnan, D. (2005). Responding to unpleasant thoughts and images: Reliability and validity of the Mindfulness Questionnaire. Manuscript under review (as cited in Baer et al., 2006).

Christensen, A., \& Jacobson, N. S. (2000). Reconcilable differences. New York: Guilford Press.

Coatsworth, J. D., Duncan, L. G., Greenberg, M. T., \& Nix, R. L. (2009). Changing parents' mindfulness, child management skills, and relationship quality with their youth: Results from a randomized pilot intervention trial. Manuscript under review.

Coleman, P. K., \& Karraker, K. H. (2003). Maternal self-efficacy beliefs, competence in parenting, and toddlers' behaviour and developmental status. Infant Mental Health Journal, 24, 126148. doi:10.1002/imhj. 10048 .

Collins, W. A. (1995). Relationships and development: Family adaptation to individual change. In S. Shulman (Ed.), Close relationships and socioemotional development (pp. 128-154). New York: Ablex.

Collins, W. A., \& Laursen, B. (2004). Changing relationships, changing youth: Interpersonal contexts of adolescent development. The Journal of Early Adolescence, 24, 55-62. doi: 10.1177/0272431603260882.

Collins, W. A., Maccoby, E., Steinberg, L., Hetherington, E. M., \& Bornstein, M. (2000). Contemporary research on parenting: The case for nature and nurture. The American Psychologist, 55, 218-232. doi:10.1037/0003-066X.55.2.218.

Conger, R. D., \& Ge, X. (1999). Conflict and cohesion in parentadolescent relations: Changes in emotional expression from early to midadolescence. Mahwah, NJ: Lawrence Erlbaum Associates Publishers.

Cowan, P. A., Powell, D., \& Cowan, C. P. (1998). Parenting interventions: A family systems perspective. In W. Damon, I. E. Sigel, \& K. A. Renninger (Eds.), Handbook of child psychology (5th ed., Vol. 4, pp. 3-72). New York, NY: Wiley.

Creswell, J. D., Way, B. M., Eisenberger, N. I., \& Lieberman, M. D. (2007). Neural correlates of dispositional mindfulness during affect labeling. Psychosomatic Medicine, 69, 560-565. doi: 10.1097/PSY.0b013e3180f6171f.

Davidson, R. J., Kabat-Zinn, J., Schumacher, J., Rosenkranz, M., Muller, D., Santorelli, S. F., et al. (2003). Alterations in brain and immune function produced by mindfulness meditation. Psychosomatic Medicine, 65(4), 564-570. doi:10.1097/01.PSY. 0000077505.67574.E3.

Dawber, T., \& Kuczynski, L. (1999). The question of ownness: Influence of relationship context on parental socialization strategies. Journal of Social and Personal Relationships, 16, 475-493. doi:10.1177/0265407599164004.

Dawe, S., \& Harnett, P. (2007). Reducing potential for child abuse among methadone-maintained parents: Results from a randomized controlled trial. Journal of Substance Abuse Treatment, 32, 381-390. doi:10.1016/j.jsat.2006.10.003. 
Dishion, T. J., Burraston, B., \& Li, F. (2003). A multimethod and multitrait analysis of family management practices: Convergent and predictive validity. In B. Bukoski \& Z. Amsel (Eds.), Handbook for drug abuse prevention theory, science, and practice. New York: Plenum.

Dix, T. (1991). The affective organization of parenting: Adaptive and maladaptive processes. Psychological Bulletin, 110, 3-25. doi: 10.1037/0033-2909.110.1.3.

Dix, T., \& Branca, S. (2003). Parenting as a goal-regulation process. In L. Kuczynski (Ed.), Handbook of dynamics in parent-child relations (pp. 167-188). Thousand Oaks, CA: Sage.

Dix, T., Ruble, D. N., Grusec, J. E., \& Nixon, S. (1986). Social cognition in parents: Inferential and affective reactions to children at three age levels. Child Development, 57, 879-894. doi:10.2307/1130365.

Dumas, J. E. (2005). Mindfulness-based parent training: Strategies to lessen the grip of automaticity in families with disruptive children. Journal of Clinical Child and Adolescent Psychology, 34, 779-791. doi:10.1207/s15374424jccp3404_20.

Duncan, L. G. (2007). Assessment of mindful parenting among parents of early adolescents: Development and validation of the Interpersonal Mindfulness in Parenting scale. Unpublished dissertation.

Duncan, L. G., Coatsworth, J. D., \& Greenberg, M. T. (2009). Pilot study to guage acceptability of a mindfulness-based, familyfocused preventive intervention. The Journal of Primary Prevention, 30(5), in press.

Eisenberg, N., Cumberland, A., \& Spinrad, T. L. (1998). Parental socialization of emotion. Psychological Inquiry, 9, 241-273. doi: 10.1207/s15327965pli0904_1.

Folkman, S. (1997). Positive psychological states and coping with severe stress. Social Science \& Medicine, 45, 1207-1221. doi: 10.1016/S0277-9536(97)00040-3.

Fonagy, P., \& Target, M. (1997). Attachment and reflective function: Their role in self-organization. Development and Psychopathology, 9, 679-700. doi:10.1017/S0954579497001399.

Fredrickson, B. L., Cohn, M. A., Coffey, K., Pek, J., \& Finkel, S. M. (2008). Open hearts build lives: Positive emotions, induced through meditation, build consequential personal resources. Journal of Personality and Social Psychology, 95(5), 1045-1062.

Goldstein, J. (2002). One dharma: The emerging Western Buddhism. San Francisco: Harper San Francisco.

Goodnow, J. J. (1985). Change and variation in ideas about childhood and parenting. In I. E. Sigel (Ed.), Parental belief systems: The psychological consequences for children (pp. 235-270). Hilsdale NJ: Lawrence Erlbaum.

Gottman, J. M. (1993). A theory of marital dissolution and stability. Journal of Family Psychology, 7, 57-75. doi:10.1037/08933200.7.1.57.

Gottman, J. M., Katz, L., \& Hooven, C. (1997). Meta-emotion: how families communicate emotionally. Mahwah, NJ: Lawrence Erlbaum.

Hastings, P. D., \& Grusec, J. E. (1998). Parenting goals as organizers of responses to parent-child disagreement. Developmental Psychology, 34, 465-479. doi:10.1037/0012-1649.34.3.465.

Hayes, S. C. (2004). Acceptance and commitment therapy and the new behavior therapies: Mindfulness, acceptance, and relationship. In S. C. Hayes, V. M. Follette, \& M. M. Linehan (Eds.), Mindfulness and acceptance: Expanding the cognitive-behavioral tradition (pp. 1-29). New York: The Guilford Press.

Hayes, A. M., \& Feldman, G. (2004). Clarifying the construct of mindfulness in the context of emotion regulation and the process of change in therapy. Clinical Psychology: Science and Practice, 11, 255-262. doi:10.1093/clipsy/bph080.

Hayes, S. C., Strosahl, K., \& Wilson, K. G. (1999). Acceptance and commitment therapy. New York: Guilford Press.
Heppner, W. L., \& Kernis, M. H. (2007). "Quiet ego" functioning: The complementary roles of mindfulness, authenticity, and secure high self-esteem. Psychological Inquiry, 18(4), 248-251.

Jacobs, J. E., Chhin, C. S., \& Shaver, K. (2005). Longitudinal links between perceptions of adolescence and the social beliefs of adolescents: Are parents' stereotypes related to beliefs held about and by their children? Journal of Youth and Adolescence, 34, 61-72. doi:10.1007/s10964-005-3206-x.

Jacobs, J. E., \& Eccles, J. S. (1992). The impact of mothers' genderrole stereotypic beliefs on mothers' and children's ability perceptions. Journal of Personality and Social Psychology, 63, 932-944. doi:10.1037/0022-3514.63.6.932.

Jha, A. P., Krompinger, J., \& Baime, M. J. (2007). Mindfulness training modifies subsystems of attention. Cognitive, Affective \& Behavioral Neuroscience, 7(2), 109-119.

Kabat-Zinn, J. (1982). An outpatient program in behavioral medicine for chronic pain patients based on the practice of mindfulness meditation: Theoretical considerations and preliminary results. General Hospital Psychiatry, 4, 33-47. doi:10.1016/01638343(82)90026-3.

Kabat-Zinn, J. (1990). Full catastrophe living: Using the wisdom of your mind to face stress, pain and illness. New York: Dell Publishing.

Kabat-Zinn, J. (1994). Wherever you go there you are: Mindfulness meditation in everyday life. New York: Hyperion.

Kabat-Zinn, J. (2003). Mindfulness-based interventions in context: Past, present, and future. Clinical Psychology: Science and Practice, 10, 144-156. doi:10.1093/clipsy/bpg016.

Kabat-Zinn, M., \& Kabat-Zinn, J. (1997). Everyday blessings: The inner work of mindful parenting. New York: Hyperion.

Karney, B. R., \& Bradbury, T. N. (1995). The longitudinal course of martial quality and stability. Psychological Bulletin, 118, 3-34. doi:10.1037/0033-2909.118.1.3.

Katz, L. F., Wilson, B., \& Gottman, J. M. (1999). Meta-emotion philosophy and family adjustment: Making an emotional correction. In M. J. Cox \& J. Brooks-Gunn (Eds.), Conflict and cohesion in families: Causes and consequences. The Advances in Family Therapy Research Series (pp. 131-165). Mahwah, NJ: Lawrence Erlbaum.

Kerr, M., \& Stattin, H. (2003). Parenting of adolescents: Action or reaction? In A. C. Crouter \& A. Booth (Eds.), Children's influence on family dynamics: The neglected side offamily relationships (pp. 121-151). Mahwah, NJ: Lawrence Erlbaum Associates.

Kim, K. J., Conger, R. D., Lorenz, F. O., \& Elder, G. H., Jr. (2001). Parent-adolescent reciprocity in negative affect and its relation to early adult social development. Developmental Psychology, 37, 775-790. doi:10.1037/0012-1649.37.6.775.

Kornfield, J. (1977). Living Buddhist masters. Santa Cruz: Unity Press.

Kuczynski, L., \& Parkin, C. M. (2007). Agency and bidirectionality in socialization: Interactions, transactions, and relational dialects. In J. E. Grusec \& P. D. Hastings (Eds.), Handbook of socialization: Theory and research (pp. 259-283). New York: Guilford Press.

Kumpfer, K. L., \& Alvarado, R. (2003). Family-strengthening approaches for the prevention of youth problem behaviors. The American Psychologist, 58, 457-465. doi:10.1037/0003-066X. 58.6-7.457.

Larson, R. W., Richards, M. H., Moneta, G., Holmbeck, G., \& Duckett, E. (1996). Changes in adolescents' daily interactions with their families from ages 10 to 18: Disengagement and transformation. Developmental Psychology, 32, 744-754. doi: 10.1037/0012-1649.32.4.744.

Laursen, B., Coy, K. C., \& Collins, W. A. (1998). Reconsidering changes in parent-child conflict across adolescence: A metaanalysis. Child Development, 69(3), 817-832. 
Laursen, B., \& Williams, V. A. (1997). Perceptions of interdependence and closeness in family and peer relationships among adolescents with and without romantic partners. In S. Shulman \& W. Andrew Collins (Eds.), Romantic relationships in adolescence: Developmental perspectives; new directions for child development (pp. 3-20). San Francisco: Jossey-Bass.

Lazar, S. (2005). Mindfulness research. In C. K. Germer, R. D. Siegel, \& P. R. Fulton (Eds.), Mindfulness and psychotherapy (pp. 220238). New York: Guilford Press.

Lazarus, R. S., \& Folkman, S. (1984). Stress, appraisal, and coping. New York: Springer.

Lazarus, R. S., \& Lazarus, B. N. (1994). Passion \& reason: Making sense of our emotions. New York: Oxford University Press.

Leary, M. R., \& Tate, E. B. (2007). The multi-faceted nature of mindfulness. Psychological Inquiry, 18(4), 251-255.

Leung, D. W., \& Slep, A. M. S. (2006). Predicting inept discipline: The role of parental depressive symptoms, anger, and attributions. Journal of Consulting and Clinical Psychology, 74, 524534. doi:10.1037/0022-006X.74.3.524.

Linehan, M. M. (1993). Cognitive behavioral treatment of borderline personality disorder. New York: Guilford Press.

Lollis, S., \& Kuczynski, L. (1997). Beyond one hand clapping: Seeing bidirectionality in parent-child relations. Journal of Social and Personal Relationships, 14, 441-461. doi:10.1177/026540 7597144002.

Ma, S. H., \& Teasdale, J. D. (2004). Mindfulness-based cognitive therapy for depression: Replication and exploration of different relapse prevention effects. Journal of Consulting and Clinical Psychology, 72, 31-40. doi:10.1037/0022-006X.72.1.31.

Maccoby, E. E. (2003). Epilogue: Dynamic viewpoints on parentchild relations-Their implications for socialization research. In L. Kuczynski (Ed.), Handbook of dynamics in parent-child relations (pp. 439-452). Thousand Oaks, CA: Sage.

Maccoby, E. E. (2007). Historical overview of socialization research and theory. In J. Grusec \& P. Hastings (Eds.), Handbook of socialization (pp. 13-41). New York: Guilford Press.

Maccoby, E., \& Martin, J. (1983). Socialization in the context of the family: Parent-child interaction. In P. H. Mussen (Ed.), Handbook of child psychology (Vol. 4, pp. 1-101). New York: Wiley.

Main, M., Cassidy, J., \& Kaplan, N. (1985). Security in infancy, childhood and adulthood: A move to the level of representation. In I. Bretherton \& E. Waters (Eds.), Growing points in attachment theory and research. Monographs of the society for research in child development (Vol 50, 1-2, Serial no. 209, pp. 66-104). Chicago: Chicago University Press.

Marvin, R., Cooper, G., Hoffman, K., \& Powell, B. (2000). The Circle of Security project: Attachment-based intervention with caregiver-preschool child dyads. Attachment \& Human Development, 4(1), 107-124. doi:10.1080/14616730252982491.

Molgaard, V., Kumpfer, K. L., \& Fleming, E. (2001). The strengthening families program: For parents and youth 10-14; A videobased curriculum. Ames, IA: Iowa State University Extension.

Mroczek, D. K. (2004). Positive and negative affect at midlife. In O. G. Brim, C. D. Ryff, \& R. C. Kessler (Eds.), How healthy are we? A national study of well-being at Midlife. Chicago: University of Chicago Press.

Neff, K. (2003). The development and validation of a scale to measure self-compassion. Self and Identity, 2, 223-250. doi: 10.1080/15298860309027.

Patterson, G. R., Reid, J. B., \& Dishion, T. J. (1992). A social interactional approach: Vol 4. Antisocial boys. Eugene, OR: Castalia.

Placone-Willey, P. M. (2002). A curriculum for mindful parenting: A model development dissertation. Unpublished dissertation.

Rahula, W. (1959). What the Buddha taught. New York: Grove Press.
Redmond, C., Spoth, R. L., Shin, C., \& Lepper, H. (1999). Modeling long-term parent outcomes of two universal family-focused preventive interventions: One year follow-up results. Journal of Consulting and Clinical Psychology, 67, 975-984. doi: 10.1037/0022-006X.67.6.975.

Roemer, L., \& Orsillo, S. M. (2007). An open trial of an acceptancebased behavior therapy for generalized anxiety disorder. Behavior Therapy, 38, 72-85. doi:10.1016/j.beth.2006.04.004.

Salzberg, S. (1995). Loving-kindness: The revolutionary art of happiness. Boston, MA: Shambhala.

Segal, Z. V., Williams, J. M. G., \& Teasdale, J. D. (2002). Mindfulness-based cognitive therapy for depression. New York: The Guilford Press.

Shapiro, S., Carlson, L. E., Astin, J. A., \& Freedman, B. (2006). Mechanisms of mindfulness. Journal of Clinical Psychology, 62(3), 373-386. doi:10.1002/jclp.20237.

Siegel, D. (2001). Toward an interpersonal neurobiology of the developing mind: Attachment relationships, "mindsight", and neural integration. Infant Mental Health Journal, 22(1-2), 6794. doi:10.1002/1097-0355(200101/04)22:1<67::AID-IMHJ3> 3.0.CO;2-G.

Siegel, D. J., \& Hartzell, M. (2003). Parenting from the inside out: How a deeper self understanding can help you raise children who thrive. New York: Penguin.

Singh, N. N., Lancioni, G. E., Winton, A. S. W., Fisher, B. C., Wahler, R. G., McAleavey, K., et al. (2006). Mindful parenting decreases aggression, noncompliance, and self-injury in children with autism. Journal of Emotional and Behavioral Disorders, 14(3), 169-177. doi:10.1177/10634266060140030401.

Skinner, B. F. (1974). About behaviorism. New York: Vintage.

Small, S. A., Eastman, G., \& Cornelius, S. (1988). Adolescent autonomy and parental stress. Journal of Youth and Adolescence, 17, 377-391. doi:10.1007/BF01537880.

Smetana, J., \& Asquith, P. (1994). Adolescents' and parents' conceptions of parental authority and personal autonomy. Child Development, 65, 1147-1162. doi:10.2307/1131311.

Smetana, J. G., Metzger, A., Gettman, D. C., \& Campione-Barr, N. (2006). Disclosure and secrecy in adolescent-parent relationships. Child Development, 77, 201-217. doi:10.1111/ j.1467-8624.2006.00865.x.

Spoth, R. L., Clair, S., Shin, C., \& Redmond, C. (2006). Long-term effects of universal preventive interventions on methamphetamine use among adolescents. Archives of Pediatrics \& Adolescent Medicine, 160, 876-882. doi:10.1001/archpedi.160.9.876.

Spoth, R. L., Redmond, C., \& Shin, C. (1998). Direct and indirect latent variable parenting outcomes of two universal familyfocused preventive interventions: Extending a public healthoriented research base. Journal of Consulting and Clinical Psychology, 66, 385-399. doi:10.1037/0022-006X.66.2.385.

Spoth, R. L., Redmond, C., \& Shin, C. (2001). Randomized trial of brief family interventions for general populations: Adolescent substance use outcomes 4 years following baseline. Journal of Consulting and Clinical Psychology, 69, 627-642. doi: 10.1037/0022-006X.69.4.627.

Spoth, R. L., Redmond, C., Shin, C., \& Azevedo, K. (2004). Brief family intervention effects on adolescent substance initiation: School-level growth curve analyses 6 years following baseline. Journal of Consulting and Clinical Psychology, 72, 535-542. doi:10.1037/0022-006X.72.3.535.

Spoth, R., Redmond, C., Shin, C., \& Huck, S. (1999). A protective process model of parent-child affective quality and child mastery effects on oppositional behaviors: A test and replication. Journal of School Psychology, 37(1), 49-71. doi:10.1016/ S0022-4405(98)00025-9.

Steinberg, L. (2004). The 10 basic principles of good parenting. New York: Simon \& Schuster. 
Taylor, T. K., \& Biglan, A. (1998). Behavioral family interventions for improving child-rearing: A review of the literature for clinicians and policy makers. Clinical Child and Family Psychology Review, 1, 41-60. doi:10.1023/A:1021848 315541.

Teti, G. M., \& Gelfand, D. M. (1991). Behavioral competence among mothers of infants in the first year: The mediational role of maternal self-efficacy. Child Development, 62, 918-929. doi: $10.2307 / 1131143$.

Wallace, B. A., \& Shapiro, S. L. (2006). Mental balance and wellbeing: Building bridges between Buddhism and Western psychology. The American Psychologist, 61, 690-701. doi: 10.1037/0003-066X.61.7.690.

Wenzel, A., \& Harvey, J. (2001). Introduction: The movement toward studying the maintenance and enhancement of close romantic relationships. In J. Harvey \& A. Wenzel (Eds.), Close romantic relationships: Maintenance and enhancement (pp. 1-10). Mahwah, NJ: Lawrence Erlbaum Associates.

Witkiewitz, K., Marlatt, G. A., \& Walker, D. D. (2005). Mindfulnessbased relapse prevention for alcohol use disorders: The meditative tortoise wins the race. Journal of Cognitive Psychotherapy, 19(3), 221-228. doi:10.1891/jcop.2005.19.3.211. 